\title{
Advances in Microscopy and Microanalysis in the Field of Forensic Firearm Examination and Identification
}

David J. Lamagna

American Forensic Technologies LLC 15 Constitution Drive, Suite 119 Bedford, N.H. 03110 d1@americanforensic.com

Forensic Firearm Examination and Identification methods and practices have not changed much since Colonel Calvin H. Goddard authored an article for the Army Ordnance entitled "Forensic Ballistics" in 1925 in which he described the use of the comparison microscope regarding firearms investigations. Phillip O. Gravelle developed the comparison microscope for use in firearm investigations with the assistance of Colonel Goddard in the early1920's. An optical comparison microscope consists primarily of two relatively low powered, two-dimensional (2D) compound microscopes joined by an ocular unit or optical bridge. This permits the results of a forensic firearm examination and comparison to be viewed in a split viewing window, enabling two separate objects such as two spent cartridge cases or bullets to be viewed simultaneously. In1935 Major Julian S. Hatcher wrote his seminal treatise on forensic firearm investigations and made the first effort to codify the methods and practices employed in this forensic discipline at that time in history, in addition to predicting futuristic technological developments. Since that era of the initial development of forensic technology for this forensic discipline, very little improvement has been made to develop and apply any modern scientific practices and equipment in this field. If anything, the technology that was initially developed, and the futuristic technological develops foreseen by the aforementioned innovators have not only not been maintained and developed, there has been an actual technological decline in this forensic discipline back to the time before Colonel Goddard had worked with Phillip O. Gravelle to develop this forensic discipline into a science. However, modern metrological methods of actually measuring toolmarks, and other surface finishes have been developed into a real science over the years, and applied to other engineering disciplines that have made use of such equipment as three-dimensional (3D) optical microscopes, white-light interferometers, confocal laser scanning microscopes, scanning electron microscopes, etc. The use of such equipment enables the qualified forensic scientist/engineer working as a firearm examiner to actually measure and compare in mathematical terms the three-dimensional toolmark, and other surface features of interest in any forensic firearm investigation. The implementation of this well-established, and validated technology into the field of forensic firearm examination and identification is critical at this point in time as the presentation of junk science in the courtrooms in the USA has become more prevalent since the OJ Simpson case, and the development of CSI style television shows, as nontechnical lawyers, judges, and law enforcement personnel attempt to introduce what they mistakenly believe is valid science into courtroom testimony in an effort to gain convictions through the use of "modern science". The National Research Council, and the National Academies of Sciences have recently addressed the problem of junk science testimony in this field. Yet, the majority of practitioners in this field are nontechnical lay people that do not understand the underlying sciences of machining science, surface metrology, microscopy, etc., and have largely ignored the NRC and NAS reports dealing with this subject matter. The limitations of the current methods and practices employed in this forensic discipline will be analyzed and discussed, and compared to the already well-established and validated metrological, microscopic and microanalytical methods and practices employed by scientist/engineers working in other well-established scientific disciplines. 